\title{
Development and Analysis of Variable Rotational Speed Transmission System for Large Wind Turbines
}

\author{
Mao-Hsiung Chiang ${ }^{1}$, Ching-Sung Wang ${ }^{1}$, Yi-Chang Chen ${ }^{1}$, Chia-Ming Chang ${ }^{2}$, Jui-Hung Liu ${ }^{2}$, Jien-Chen Chen ${ }^{2}$, \\ Meng-Ru Wu ${ }^{2}$, Chih-Hsun Peng ${ }^{2}$ \\ ${ }^{1}$ Department of Engineering Science \& Ocean Engineering, National Taiwan University, Taipei, Taiwan \\ ${ }^{2}$ Industrial Technology Research Institute, Hsinchu, Taiwan
}

\begin{abstract}
Gear boxes and direct-drive systems are commonly used in the transmission of large wind turbines. The components such as blades, rotor, gear box and the generator should be set up coaxially in the nacelle. Thus, the total weights of the nacelle increases with the size of the wind turbines. This research develops a hydrodynamic variable rotational speed transmission system combining with planetary gear-sets and the hydrodynamic transmission system for a $2 \mathrm{MW}$ wind turbine. The nonlinear dynamic models of hydrodynamic transmission system and planetary gear-sets are derived firstly. The dynamic simulation analysis for the feedback type hydrodynamic transmission system (FHDTS) with feedback planetary gear-sets is implemented using MATLAB/ SIMULINK. Finally, the closed-loop variable rotational speed control simulation combined with an intelligent controller can be achieved for evaluating the feasibility.
\end{abstract}

Keywords-hydrodynamic transmission system; torque converter; planetary gear-set; feedback type; rotational speed control.

\section{INTRODUCTION}

The hydraulic transmission system can be classified to different types: direct-driven hydrostatic transmission system, feedback hydrodynamic transmission system, and feedback hydrostatic transmission system. The directdriven hydrostatic transmission system for large wind turbines has been investigated in [1]. By using variable displacement pumps and motors, this research reduced the total weights of transmission system. Furthermore, the variable displacement motor could maintain a steady generator-side speed to make a stable output. Despite of the hydrostatic system, hydrodynamic system combined with pump and motor together to expand a larger volume of container. Besides, the efficiency can be enhanced because that the hydrodynamic system only needed single hydraulic unit while the hydrostatic system contained two machines (pump, motor). In 1977, Zarotti and Nervenga [2] analysed the influence on torque changed by the impeller angles. Subsequently, Kesy, et al based on the high adaptive characteristic, building a mathematic model to analyse the damping effect of the transmission system [3]. Since 2000, Behrens, et al [4] simplified the nonlinear dynamics and J.Murin applied it to build up a hydrodynamic transmission model with diesel engine.

Therefore, the main contribution is to develop an enhanced hydrodynamic transmission model that can be used in the large wind turbine including model analysis and validation. Besides, by using the control theory, we not only verify the system can be applied to the large wind turbine transmission, but also improve the dynamic response and the tracking performance.

\section{DESIGN OF HYDRODYNAMIC TRANSMISSION SYSTEM}

To design a model, the architecture block diagram is required. As figure 1, this transmission system consists of a group of feedback planetary gear-sets components and a hydrodynamic unit. The rotor combines with the planet gear in first-side(V1) then the planetary gear-set directly derive the generator and the hydrodynamic system in the second-side(V3). More precisely, the planetary gear-set was used as gear shifting to change the rotational speed while the hydrodynamic unit was loaded by the secondside rotor and compensated as a feedback system. Through these procedures, we could output a desired generator-side speed by the compensation of hydrodynamic output speed (V2) even if the first-side speed is unstable or fluctuating. Therefore, the controllability of the hydrodynamic system leads dominance in this study. 


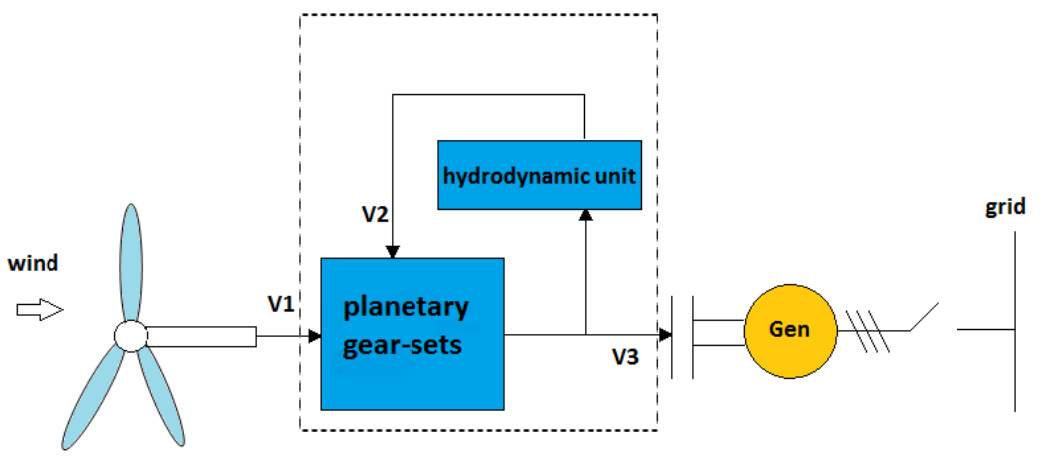

Figure 1. Hydrodynamic transmission system diagram

In this study, there is another important part in transmission to accelerate the rotor speed, "the planetary gear-set”. A simple planetary gear, as shown in Fig. 2, contains a sun gear, planet-pinion gears, and a ring gears. The input and output speed can connect to any two of members. Under different circumstances, we can decide whether to accelerate it or not by deciding which member should be connected with. However, the accelerating ratio depends on the diameter of gears which is fixed in the beginning. In order to reach the speed instantly, we figured out a novel model by combining the hydrodynamic system and planetary gear-sets together. The turbine would drive the rest of member to change the output speed. We could know the designated diagram of feedback hydrodynamic transmission system using in 2MW wind turbine.

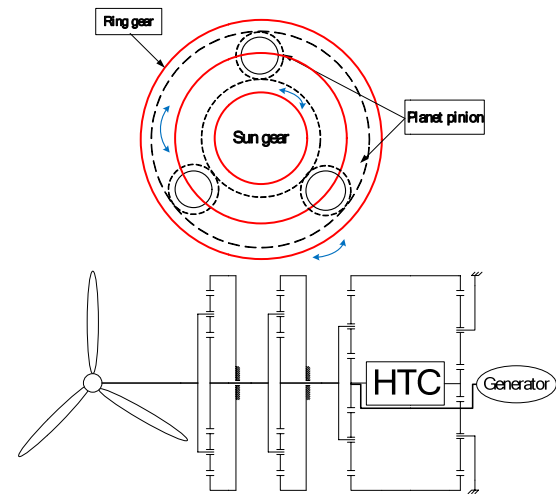

Figure 2. Planetary gear-set and feedback hydrodynamic transmission system using in $2 \mathrm{MW}$ wind turbine

\section{Nonlinear Dynamic Mathematic Model OF FHDTS}

In this section we derive the mathematic models of hydrodynamic systems including torque converting equation, continuous equation, and other dynamic equations.

\section{A. Torque converting equation}

The volume flow $Q$ passing through the blade and turbine wheel can be generated when a torque $M_{p}$ drove the pump wheel. Subsequently, the mass flow rate was related to the angular momentum $L$. The pump side and turbine side torque $M_{p}, M_{T}$ can be simplified by neglecting blade curvature and the blade wheel.

$$
\begin{gathered}
\dot{L}_{P X}=\rho Q \omega_{P} r_{P x}^{2} \\
\dot{L}_{T x}=\rho Q \omega_{T} r_{T x}^{2} \\
M_{T}=\dot{L}_{T x}-\dot{L}_{P x} \\
=\rho Q\left(\omega_{T} r_{T x}^{2}-\omega_{P} r_{P X}^{2}\right) \\
=-M_{P}
\end{gathered}
$$

Note that symbol $\rho$ is represented as oil density and $r$ is the radius of intersection area. The subscript $x$ and $e$ are expressed as a direction of exhalation and inhalation. While the subscript $P$ and $T$ are symbols to represent pump side and turbine side.

\section{B. Continuous equation}

After the previous equations are enhanced, we can calculate and derive the internal pressure equations. The internal pressure is integrated by the internal volume flow, and the hydraulic power $P$ is consistent with the product of internal pressure $\Delta p$ and volume flow $Q$.

$$
\begin{aligned}
\Delta p_{P} & =\frac{P_{P}}{Q}=\frac{M_{P} \omega_{P}}{Q} \\
& =\rho \omega_{P}^{2} r_{P X}^{2}+\rho \omega_{P}\left(\frac{r_{P X} \tan \alpha_{P X}}{A_{P X}}-\frac{r_{R x} \tan \alpha_{R X}}{A_{R X}}\right) Q \\
\Delta p_{T}= & \frac{P_{T}}{Q}=\frac{M_{T} \omega_{T}}{Q} \\
= & \rho \omega_{T}\left(\omega_{T} r_{T x}^{2}-\omega_{P} r_{P X}^{2}\right)+\rho \omega_{T}\left(\frac{r_{T X} \tan \alpha_{T X}}{A_{I X}}-\frac{r_{P X} \tan \alpha_{P X}}{A_{P X}}\right) Q
\end{aligned}
$$

However, there are two kinds of factor that made the energy lost, such as the fluid abrasion and impulsive abrasion. The fluid abrasion is related to its own factors like velocity, density, and frictional coefficient, while the impulsive abrasion occurred when the fluid passed through different boundary layers which are caused by different angles of blade. This effect is coherent with the energy consuming phenomenon in pipe. Therefore, we 
derive the following equations with the concepts that we mentioned before.

$$
\begin{gathered}
\Delta p_{f}=\frac{1}{2} \rho C_{f} Q^{2} \\
\Delta p_{P}+\Delta p_{T}=\Delta p_{f}+\Delta p_{s P-T}+\Delta p_{s T-R}+\Delta p_{s R-P} \\
\Rightarrow I Q^{2}+\left(H \omega_{T}-G \omega_{P}\right) Q-\left(E \omega_{P}^{2}+F \omega_{T}^{2}\right)=0
\end{gathered}
$$

$$
Q=\frac{-\left(H \omega_{T}-G \omega_{P}\right)+\sqrt{\left(H \omega_{T}-G \omega_{P}\right)^{2}+4 I\left(E \omega_{P}^{2}+F \omega_{T}^{2}\right)}}{2 I}
$$

To simplify the equation, we use some variables as substitution in Eq.(6) (8) which can be shown in Table 1.:

then we get an equation of internal volume flow as,

TABLE I. THE SUBSTITUTION OF VARIABLES

$\begin{array}{cc}I=\frac{1}{2} \rho\left[\left(\frac{\tan \alpha_{P x}}{A_{P x}}-\frac{\tan \alpha_{T e}}{A_{T e}}\right)^{2}+\left(\frac{\tan \alpha_{T x}}{A_{T x}}-\frac{\tan \alpha_{R e}}{A_{R e}}\right)^{2}+\left(\frac{\tan \alpha_{R x}}{A_{R x}}-\frac{\tan \alpha_{P e}}{A_{P e}}\right)^{2}+C_{f}\right] \\ H=\rho\left(\frac{r_{T e} \tan \alpha_{T e}}{A_{T e}}-\frac{r_{R e} \tan \alpha_{R e}}{A_{R e}}\right) & F=\frac{1}{2} \rho\left(r_{T x}^{2}-r_{T e}^{2}\right) \\ G=\rho\left(\frac{r_{T e} \tan \alpha_{T e}}{A_{T e}}-\frac{r_{P e} \tan \alpha_{P e}}{A_{P e}}\right) & E=\frac{1}{2} \rho\left(r_{P x}^{2}-r_{P e}^{2}\right)\end{array}$

With Eq.(9), we can substitute the input torque and input angular speed into it to get the output torque and angular speed.

\section{SimULATION RESUltS}

The simulation results were used to verify the models derived. Meanwhile, by compensating with the controller, the tracking performance could be enhanced even if the nonlinearity and coupling phenomenon. The closed loop feedback control compensation could not only linearize the FHDTS, but also compensate the tracking
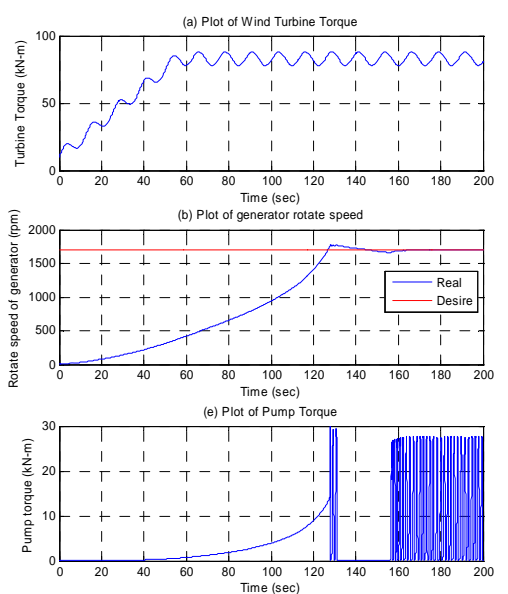

performance. The controller was based on fuzzy sliding mode control theory with high robustness and high response.

The realistic wind condition was random and unsteady. In this section, we designed a mixed trajectory as a random wind speed. The illustration of Fig. 3 was given as follows. The speed shown in Fig. 3(b) can remain stable even if the input loading was oscillated. The results showed that by compensating with a controller, the FHDTS performed with high robustness and high disturbance rejection.

Figure 3. Various loading torque closed-loop response: (a) input torque (b) tracking performance (c) tracking error (d) input voltage (e) pump side reacting torque (f) output torque

\section{CONCLUSION}

This study developed a feedback type hydrodynamic transmission system. Through the combination of planetary gear-sets, we successively applied to the 2MW wind turbine transmission. Furthermore, we verified the validity by open-loop dynamic simulation and the nonlinearity could be conquered by the controller in closed-loop dynamic simulation. The dynamic simulation analysis for the feedback type hydrodynamic transmission system (FHDTS) with feedback planetary gear-sets was implemented using MATLAB/ SIMULINK. Finally, the closed-loop variable rotational speed control simulation combined with an intelligent controller could be achieved for evaluating the feasibility. 


\section{ACKNOWLEDGEMENTS}

This study was supported by Bureau of Energy, Ministry of Economic Affairs

\section{REFERENCES}

[1] B. Boukhezzar, L. Lupu, H. Siguerdidjane, M. Hand, "Multivariable control strategy for variable speed, variable pitch wind turbines", Renewable Energy volume 32, Issue 8, Page(s):1273-1287, July 2007.

[2] Jianzhong Zhang, Ming Cheng, Zhe Chen, "Design of Wind Turbine Controller by Using Wind Turbine Codes", International Conference on Electrical Machines and System, 2008 (ICEMS2008), Page(s):2591-2595, Oct. 2008.

[3] R. Fadaeinedjad, G. Moschopoulos, M. Moallem, "Simulation of a Wind Turbine with Doubly-Fed Induction Machine Using FAST and Simulink", International Symposium on Industrial Electronics (ISIE 2006), Page(s):2648-2653, July 2006.

[4] R. Fadaeinedjad, M. Moallem, G. Moschopoulos, "Simulation of a Wind Turbine with Doubly Fed Induction Generator by FAST and Simulink", IEEE Transactions on Energy Conversion, Vol. 23, Issue 2, Page(s): 690-700, June 2008.

[5] Sayooj B Krishna, S. V. Reeba, "Simulation of Wind Turbine with Switched Reluctance Generator by FAST and Simulink", 10th
National Conference on Technological Trends (NCTT09), Page(s): 106-111, Nov 2009.

[6] R.K.Lu, C.R.Chang, Load Computation of a 150kWWind Turbine by IEC-61400-1via FAST/SIMULINK”, 2009 Taiwan Wind Energy Conference,Taipei, Taiwan, Page(s): 1-6, Dec. 2009.

[7] G. Mandic, A. Nasiri, "Modeling and Simulation of a Wind Turbine System with Utlracapacitors for Short-Term Power Smoothing”, IEEE International Symposium on Industrial Electronics (ISIE 2010), Page(s): 2431-2436, July 2010.

[8] R. Fadaeinedjad, G. Moschopoulos, A. Ghareveisi, "Utilizing a STATCOM to Prevent the Flicker Propagation in a Wind Power System”, IEEE Energy Conversion Congress and Exposition (ECCE 2010), Page(s):679-686, Sept. 2010.

[9] scheme applied to robot manipulator”, Int. J. Control, Vol. 45, no. 45, Page(s): 1197-1209, 1987

[10] T. F. Chang. K. L . Shi, Y. K. Wong and S. L . Ho, "Modelling and Simulation of The Three-phase Induction Motor Using Simulink," International Journal of Eletric Engineering vol. 36, pp. 163-172, 1999.

[11] Garbriele Michalke, Anca D. Hansen, Thomas Hartkopf, “Control strategy of variable speed wind turbine with multiple permanent magnet synchronous generator", European Wind Energy Conference and Exhibition EWEC, Milano, Page(s): 1-8, May 2007. 